\title{
Generativity: The New Frontier for Information and Communication Technology Literacy
}

\author{
Jorge Pérez and Meg Coffin Murray \\ Kennesaw State University, Kennesaw, GA, USA \\ jperez@kennesaw.edu mcmurray@kennesaw.edu
}

\begin{abstract}
Information and communication technology literacy is increasingly referred to as the fourth literacy. However, it is neither as well understood nor as readily assessed as reading, writing, and arithmetic. This paper argues that better understanding and more effective measurement of ICT literacy are needed to gauge readiness to both pursue higher education and enter the workforce. The paper builds on existing definitions of ICT literacy by introducing a model that extends the dimensionality of the construct. The model posits that skills and knowledge, along with attitudes toward IT, coalesce in the context of reflective self-awareness and purposeful intent to allow a computer user to achieve generativity - the ability to generate new skills and knowledge that form the basis for creativity. Literacy, aptitude, and creativity are overlaid on the model to give meaning to the complex, iterative processes by which users interact with and learn about information technology artifacts and concepts. In the absence of robust theoretical foundations and effective standardized assessments, ICT literacy will continue to play a fourth, barely audible fiddle to its three more established counterparts.
\end{abstract}

Keywords: ICT literacy, IT literacy, computer literacy, information literacy, IT education.

\section{Introduction}

Reading, writing, and arithmetic skills are measured via standardized assessments and broadly accepted as indicators of scholastic aptitude or educational preparedness. While competency in a fourth area - information and communication technology - is increasingly critical to success in any occupation or educational discipline, popular standardized aptitude tests have yet to evolve to encompass the fourth literacy. Moreover, while numerous IT certification tests are extant, the ETS ICT Literacy Assessment is likely the only widely known standardized IT aptitude test. Critical information technology competencies are often taken for granted, to the detriment of students who lack computing and Internet skills (Katz \& Macklin, 2007; Murray \& Pérez, 2006). Given the importance of information technology as a fundamental driver of societal and economic change, universities are again pondering what defines ICT literacy and what specific skills are needed to effectively utilize computers

Material published as part of this publication, either on-line or in print, is copyrighted by the Informing Science Institute. Permission to make digital or paper copy of part or all of these works for personal or classroom use is granted without fee provided that the copies are not made or distributed for profit or commercial advantage AND that copies 1) bear this notice in full and 2) give the full citation on the first page. It is permissible to abstract these works so long as credit is given. To copy in all other cases or to republish or to post on a server or to redistribute to lists requires specific permission and payment of a fee. Contact Publisher@InformingScience.org to request redistribution permission.

(Katz \& Macklin, 2007).

Most students today are exposed to computers and have experience using the Internet. But a gap is emerging between cursory, functional use and deeper, analytical understanding of computing technologies. The 2009 ECAR Study of Undergraduate Students and Information Technology found that $98 \%$ of 30,616 college students from the US 
and Canada who responded to the survey own a personal computer (Smith, Gail, \& Caruso, 2009). Nine of ten of these respondents also reported using a social networking site with fairly high frequency. Less than half of these students, however, reported that the IT skills they learned in their courses had adequately prepared them for the workplace. Dednam (2009) reported that $83 \%$ of students who took a basic computer literacy assessment test upon university entrance did not pass the test at the threshold score of $65 \%$. Braddlee and Matthews-DeNatale (2006) found that student self-reported IT ability ratings were much higher than actual performance scores. Similar discrepancies have also been reported by Hilberg and Meiselwitz (2008) and Madigan, Goodfellow, and Stone (2007). We are beginning to recognize that IT use does not equate to IT competence (Oblinger \& Hawkings, 2006).

\section{Efforts to Assess IT Literacy}

In many societies, reading, writing and arithmetic abilities are readily assessed, whereas widespread assessment of IT literacy is just beginning to emerge (Murray \& Pérez, 2006). There are several initiatives underway that attempt to address the need to amplify IT skills in higher education. In the United States, it has been mandated that technological literacy will become a part of the assessment of educational progress of pre-college level students. 'Technological literacy' will become a formal part of the National Assessment of Educational Progress (NAEP), also known as the 'Nation's Report Card,' which gauges the educational progress of elementary and secondary students. The assessment will be instituted nationwide in 2012. A draft of the instrument has been made available for public review (National Assessment Governing Board, 2009). Technological literacy, as defined in this report, is broad and inclusive: "Technological literacy is the capability to use, understand, and evaluate technology as well as to apply technological concepts and processes to solve problems and reach one's goals" (National Assessment Governing Board, 2009. p. v). ICT literacy is included as one component of technological literacy. The instrument will define assessment questions for upper elementary (grade 4), middle school (grade 8), and end of secondary (grade 12). The preliminary framework focuses on student ability to choose the right ICT tools to solve problems, while recognizing the relative merits of different sources of information. However, in its attempt to capture the conceptual, it forgoes evaluation of skills - the ICT tools in use. Planned assessment questions will be framed in the context of societal issues and problems.

Australia completed its first national assessment of ICT literacy for pre-college level students in 2005 (Australian Ministerial Council on Education, 2007). Australia's national goals for education include that students become "confident, creative and productive users of new technologies, particularly information and communication technologies, and understand the impact of those technologies on society" (p. i). ICT literacy is defined as, "the ability of individuals to use ICT appropriately to access, manage and evaluate information, develop new understandings, and communicate with others in order to participate effectively in society" (p.vii). The assessment report concludes that "[o]ne should not assume that students are uniformly becoming adept because they use ICT so widely in their daily lives" (p. xiv). Further, the report notes that students use ICT in a limited way, such as communicating with peers and looking up information on the Internet. However, there is "much less frequent use of applications that involve creating, analyzing or transforming information" (p. xiv.).

The California ICT Digital Literacy Assessments and Curriculum Framework (California Emerging Technology Fund, 2008) is the result of a statewide effort to "provide a standardized approach for assessment, diagnosis, and continuous improvement of basic information and communications (ICT) digital literacy skills for students and the workforce" (p. 3). The framework recommends assessment of university students, but it does not propose a specific instrument. Several universities have begun to use the ETS technology literacy test. However, the California report cited that 
there were no assessment instruments available that encompass the "overarching standardized continuum of skills" comprising ICT digital literacy. The articulation that ICT literacy is a continuum represents an evolution beyond existing definitions of ICT literacy.

A recognition of the need for ICT literacy reaches across the globe. Information and communication technologies are drivers for economic growth in both developed and developing countries. ICT has also been cited as a contributor to social and political transformation and an enabler of innovation (Spence \& Smith, 2009). Today's students need to become adept at '21st century skills,' which include using ICT to gather and assess information, collaborate, innovate, think critically, and solve problems ("Measuring 21st Century Skills," 2009). The Partnership for 21st Century Skills goes on to identify the challenges, such as how these skills would be taught in the core curriculum and how student attainment would be measured. These are among the questions that must be addressed by a re-conceptualization of the ICT literacy construct. What seems to be missing from the many discussions and investigations of how to define ICT literacy is a model that both captures the dimensions of the construct, and incorporates users, roles, and tasks.

\section{Defining ICT Literacy}

Computer literacy has been a been a topic of discussion since the early 1960 s, when it was considered to be a component of computer science education most often equivocated with programming skill (Neill, 1977). However, even then, there was interest in developing "computer appreciation" among liberal arts undergraduates. By the early 1970s, the term computer literacy had officially been coined, and discussions about the computer literacy construct began to take a more philosophical base. In 1972, the National Science Foundation instituted the Computer Impact on Society Section of the NSF Office of Computing Activities and charged it with investigating the impact of computers on organizations and individuals. The goals of this program were to explore how computers and information technology were being used to support management decision making and how these technologies were influencing lifestyles (Lykos, Morgan, \& Weingarten, 1973). The growing awareness of computing technologies translated into "calls for action" to develop a computer literate society. This mantra was rationalized along three dimensions: the pervasiveness of computers affecting most facets of society, the impact of technology on public policy, and the need to prepare workers for new occupations in the computing fields (Neill, 1977). A computer literate society was seen as the way to eliminate the potential for "a computer culture unable or (unwilling) to communicate its secrets with the non-computer culture" (Neill, 1977, p. 175).

The 1980s saw a flurry of activities aimed at the development of computer literate societies. Much of this work centered on the development of computer literacy curriculum. However, by the end of the decade, controversy arose over these curriculum initiatives. In the paper, "What is Computer Literacy: The Sham, The Imposter and the Misdirected," Cohen (1987) argued that these curricula did not address the true essence of computer literacy, but instead were "baby computer science" ( $p$ 321). Further, he perceived that computer literacy does not mean "literate in computers" but rather literate "in the study of information, its uses and its processing" (p. 321).

In the early 1990s, a wave of computer literacy courses focused on skill development in a small set of applications - primarily word processing, spreadsheet, and presentation software. These courses became identified as vocational training and were often eliminated from college curricula. Although the World Wide Web became popular in the early 1990s, it was not until later in the decade that competencies related to Internet use were incorporated into the computer literacy construct. At the same time, the focus shifted from basic computer literacy to defining degree programs in computing that would educate professionals for IT jobs. Required computer literacy courses began to disappear as many educators believed that students were entering the university well-versed in basic computer usage (Dednam, 2009; Smith et al., 2009). However, universities 
are finding that many students lack the IT skills they need to succeed in their academic pursuits and in their careers (Pérez \& Murray, 2006). While institutions of higher education have espoused the need to graduate people who demonstrate a set of IT competencies, there is no standard set of computer skills that clearly define the IT competent individual. Consequently, there has been a resurgence of interest in defining what computer literacy means today.

One of the earliest official definitions of computer literacy in the US was tendered by the National Center for Educational Statistics in 1983: "Computer literacy may be defined as whatever a person needs to know and do with computers in order to function competently in our information based society" (Halaris \& Sloan, 1985, p. 320). In 1996, the US government again tried to define computer literacy, recasting it as technology literacy. The U.S. Department of Education (1996) defined technology literacy as "the ability to use computers and other technology to improve learning, productivity and performance" (p. 5). While these definitions hold many truths, they are too general in nature to serve much practical purpose.

To overcome the ambiguity in general definitions, some have associated computer literacy with the ability to use a computer. Others perceive it to include a basic awareness of computer terminology, while still others have implied that computer literacy has a more functional meaning. For example, one definition of computer literacy recently published in the ACM SIGCSE Bulletin defined computer literacy as an "individual's ability to operate a computer system, have basic understanding of the operating system to save, copy, delete, open, print documents, format a disk, use computer applications software to perform personal or job-related tasks, use Web browsers and search engines on the Internet to retrieve needed information, and communicate with others by sending and receiving email" (Gupta, 2006, p. 115). Further, a computer literate student should be able to use a computer to conduct research and solve problems related to the student's major discipline. In this regard, computer literacy has been associated with application literacy the ability to use specific software applications such as word processing, spreadsheet or presentation software.

Other terms that have emerged capture or approximate the notion of computer literacy: technology literacy, computer fluency, computer competence, cyber literacy, digital literacy or electronic-literacy. Electronic, digital, or technology literacy is associated with activities such as reading, writing, exchanging information and communicating in online environments. Cyber literacy has been used to describe "someone who can fully participate in cyber-society as an informed citizen" (Stiller \& LeBlanc, 2006 p. 5). Cyber literacy shifts from computer-centric to Internetcentric. The rationale for so many different terms is that no one of these terms captures the full essence of what is meant by computer literacy.

Hoffman, Blake, McKeon, Leone, and Schorr, (2005) provide an expanded definition of computer literacy that encompasses both "information literacy, the ability to evaluate information found online, and critical computer literacy, the ability to incorporate computing technology in support of critical thinking" (p. 164). The Association of College and Research Libraries (2003) defines information literacy as "a set of abilities requiring individuals to recognize when information is needed and have the ability to locate, evaluate and use effectively the information needed," and computer literacy as "rote learning of specific hardware and software applications."

Recognizing the growing importance of information and communication technologies, and their role in transforming "life, learning and work," the Educational Testing Service (ETS) convened in 2001 an international panel of experts from public and private organizations and academe to study the relationship between ICT and literacy. The goal was to define a framework for ICT literacy that could be mapped to the development of a large-scale ICT assessment instrument. The work of the ETS panel revealed some interesting shifts in the concept of literacy. First, the panel proposed that technology-based skills should be included in considerations of what constitutes a 
literate populace. In addition, the concept of the digital divide was expanded beyond the notion of access, to include reading, numeracy, and problem-solving as prerequisites to ICT literacy. Finally, it was noted that ICT literacy cannot be confined to the mastery of technical skill. Rather, ICT literacy must be viewed as a continuum of skills and abilities that incorporates critical cognitive skills and application of knowledge. In other words, literacy should no longer be viewed as an either/or proposition. Ultimately, the panel defined ICT literacy from a perspective of functional and effective use of information. Specifically it states that "ICT literacy is using digital technology, communications tools, and/or networks to access, manage, integrate, evaluate, and create information in order to function in a knowledge society" (ICT Literacy Panel, 2007, p. 2). Each of the active verbs in the definition is further refined into one of the five critical components of ICT literacy. Access refers to knowing about and knowing how to collect and retrieve information. Manage connotes the application of an organizing or classifying scheme. Integrate captures the interpretation and representation of information. Evaluate relates to making judgments about information quality, relevancy, usefulness, and efficiency. Creation refers to the generation of information. These components are encapsulated within three proficiencies: cognitive proficiency (demonstrated by literacy, numeracy, problem solving and spatial/visual literacy), technical proficiency (foundational knowledge of hardware and software), and ICT proficiency (integration of cognitive and technical skill). In this context, ICT proficiency is viewed as an enabling proficiency that, as it matures, leads to innovation, transformation, and even societal change.

The Association of American Colleges and Universities (AACU) acknowledged the relevance of computer skills in higher education (Ehmann, 2004). Specifically, the AACU identified five key educational outcomes of a liberal education and articulated how computing technologies are necessary to support the attainment of these objectives. The outcomes focus on the development of 1 ) strong analytical skills, 2) enhanced inquiry practices gained via hands-on experience, 3) intercultural knowledge and collaborative problem-solving skills, 4) civic responsibility acquired via the connection of knowledge, skills, values and action, and 5) integrative thinking and the ability to transfer skills and knowledge. Activities to foster attainment of student outcomes are proposed, and assessment is accomplished via an online portfolio. The work of the AACU marks a shift from training on functional computer usage skills toward education on critical, problem-solving use of IT.

Cesarini (2004/2005) describes information technology literacy as an iterative, positively reinforcing meta-literacy that is greater than the sum of its parts. He posits that IT literacy is achieved through understanding the causes and effects of IT on society. Further, he argues that closing the gap between exposure and understanding presents one of the most compelling challenges in modern society, impacting the generation most influenced by technological change.

Mason and McMorrow (2006) suggest that computer literacy has two distinct components: awareness and competence. Awareness refers to understanding how computer technology has evolved in various disciplines and impacts individuals and society. Awareness also encompasses the development of attitudes toward computers in general and toward related societal issues such as privacy, security, and social networking. Competence, which has a more technical and functional connotation, refers to understanding computer hardware and having basic skills in the use of software, Internet tools, and mobile devices. The authors assert that an individual must have both awareness and competency to be considered computer literate.

Owing in part to a long history of assessing competencies in reading, writing, and arithmetic as surrogates for scholastic aptitude, there is more or less general concurrence on what constitutes these forms of literacy. The same cannot be said for ICT literacy. There is movement toward conceptualizing ICT literacy as an amalgam of digital literacy, media literacy, information literacy, and so on (Markauskaite, 2006). However, a definition of ICT literacy has been neither widely adopted nor codified in a universally adopted standardized assessments such as the SAT and 
ACT. Development of the model introduced below was guided by recognition of the need for a comprehensive, general definition of ICT literacy.

\section{A Model of ICT Literacy}

Bloom's (1956) taxonomy of learning provides a way to frame operational definitions of literacy via the domains of knowledge, skills, and attitudes. Knowledge represents understanding, comprehension, and purposeful intent. Skills equate to the ability to perform a task or function. Attitudes reflect perceptions of value, appreciation, and confidence. While each of these elements contributes to literacy, they fall short of encompassing the totality of ICT literacy. The model of ICT literacy introduced in this paper (Figure 1) posits that skills and knowledge, along with attitudes toward IT, coalesce in the context of reflective self-awareness and purposeful intent to allow one to achieve generativity - the ability to generate new skills and knowledge that form the basis for innovation and creativity. Generative technologies have been described as characterized by adaptability, ease of mastery, accessibility, transferability, and leverage (Zittrain, 2006). This paper views generativity through a lens that casts the user in a central role, and views task and technology as context.

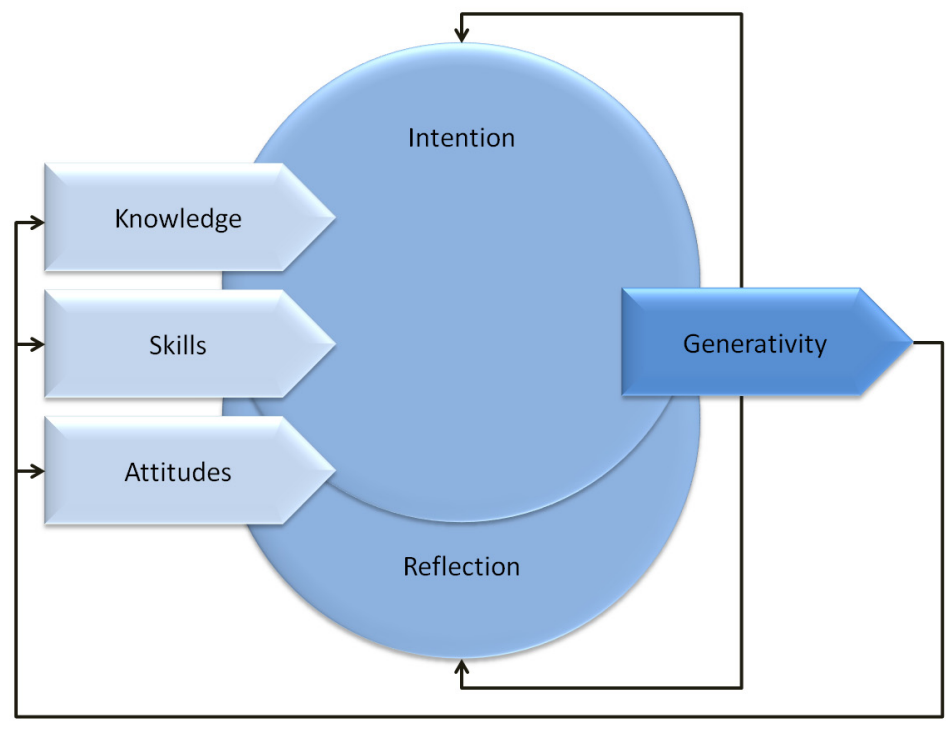

Figure 1: A model of ICT literacy

The concept of knowledge has been explored by philosophers and epistemologists throughout the ages. Perhaps most relevant to this paper is the assertion that knowledge resides in the cognitive domain (Bloom, 1956). Terms often associated with knowledge include comprehension, application, analysis, synthesis, and evaluation (Bloom, 1956). In the context of ICT literacy, Wen and Shih (2008) proposed that knowledge encompasses explaining, organizing, analyzing, assessing, and synthesizing.

Skills are a learned capacity acquired through practice - the ability to do something. Most current IT certification tests focus on skills. Typically the certification tests divide skills into the categories of hardware, basic operating system functions, productivity software tasks, and Internet use (Murray \& Pérez, 2006). While demonstrating the ability to perform specific tasks is a prerequi- 
site to ICT literacy, simply being able to master basic computer functions is not enough to describe one as computer literate.

Attitudes are learned tendencies that incorporate affective and behavioral dimensions (Necessary \& Parish, 1996). In the context of ICT literacy, attitudes are often framed relative to computer anxiety, on one hand, and how much one likes computers and appreciates their role in society, on the other hand. Most ICT literacy assessments focus on knowledge and skills but do not address attitudes. However, as important precursors to behavior, attitudes impact motivation to learn about and use computers (Wen \& Shih, 2008).

Knowledge, skills, and attitudes are depicted in the model as impacting generativity via reflection and intention. Jonassen and Land (2000) defined learning as "conscious activity guided by intentions and reflections" (p. v). Further, learning is a "willful, intentional, active, conscious, constructive practice that includes reciprocal intention - action - reflection activities" (p. v). Extending this reasoning to the model of ICT literacy introduced in this paper, a computer user ascribes meaning to knowledge, skills, and attitudes via intentional self-awareness and purposeful reflection. Thus, meaning becomes the foundation for generativity.

Ericson (1950) coined the term generativity to denote a concern for establishing and guiding the next generation. Most often associated with creativity, generativity was applied by Zittrain (2006) to computing and Internet technologies via five principal factors: leverage, adaptability, ease of mastery, transferability, and accessibility. Leverage describes the extent to which a generative technology object enables valuable accomplishments. Adaptability refers to how readily a technology can be modified to broaden its use. Ease of mastery reflects how easily technology might be mastered, adopted, adapted, and deployed. Accessibility connotes the availability of a technology. Finally, transferability refers to how easily modifications to a technology can be assimilated by users, particularly non-experts. In a holistic sense, technological generativity encompasses the ability to generate new, valuable uses of technology that are easy to distribute and provide the sources of further innovation (Zittrain, 2006).

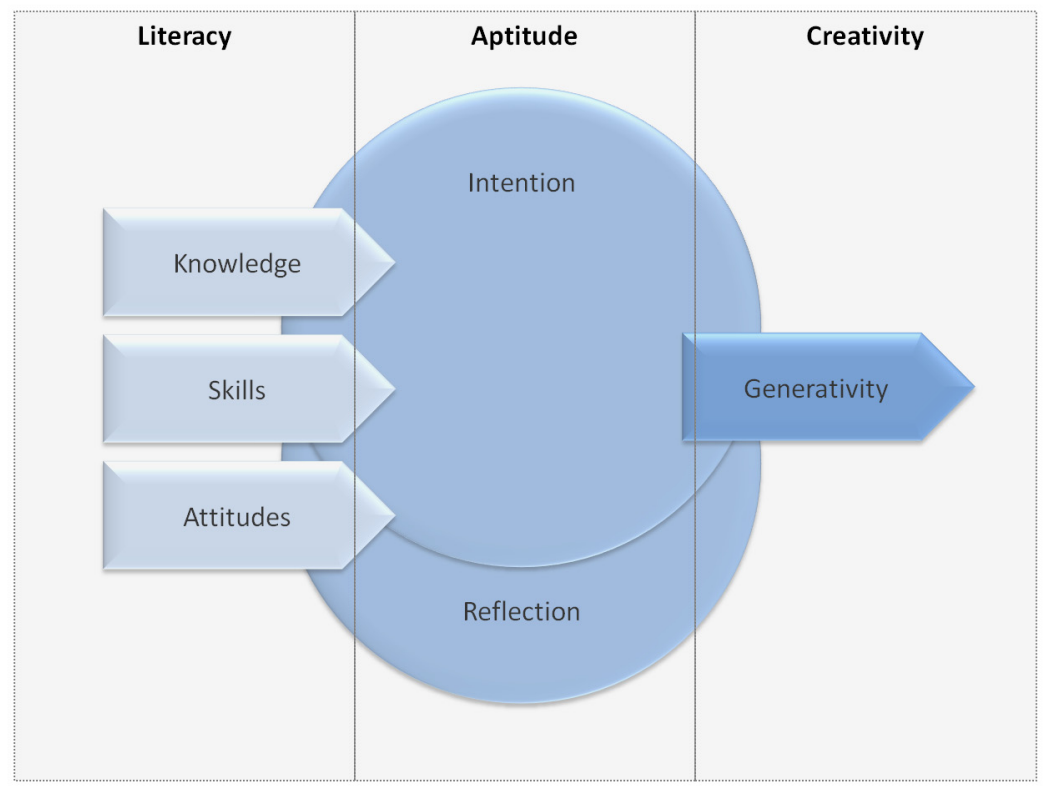

Figure 2: Literacy, aptitude, and creativity overlaid on a model of ICT literacy 
The proposed model of ICT literacy depicts knowledge, skills, and attitudes driving intention and reflection, which in turn create the potential for generativity. In Figure 2, the dimensions of literacy, aptitude, and creativity are overlaid on the model to illustrate movement from foundational to self-aware to innovative interactions with computer technologies. Literacy encompasses knowledge, skills, and attitudes; aptitude captures reflection and intention; generativity connotes the potential for creativity. Although the model shows movement from literacy to aptitude to creativity, there is no intent to imply linearity in the relationships among these complex constructs. The overlay of literacy, aptitude, and creativity is meant to give meaning to the complex, iterative processes by which users interact with and learn about information technology artifacts and concepts - processes that are neither linear nor deterministic.

\section{Conclusion}

ICT literacy, which is increasingly referred to as the fourth literacy, is neither as well defined nor as readily assessed as reading, writing, and arithmetic. This paper argues that better understanding and more effective measurement of ICT literacy are needed to gauge readiness to both pursue higher education and enter the workforce. The paper builds on existing definitions of ICT literacy by introducing a model that extends the dimensionality of the construct. The model posits that knowledge, skills, and attitudes interact via intention and reflection to yield generativity - the capacity for ICT creativity. Literacy, aptitude, and creativity are overlaid on the model to reframe these concepts in light of generativity.

The model implies some compelling opportunities for future research. For instance, it would be illuminating to map the model to specific learning outcomes and explore the degree to which ICT literacy courses in higher education address the realms of aptitude and generativity. Another fruitful avenue of investigation would involve operationalizing constructs in the model and testing hypotheses about their interrelations. Lastly, the model suggests an imperative to develop ICT assessments that encompass literacy, aptitude, and creativity via knowledge, skills, attitudes, reflection, intention, and generativity. In the absence of robust theoretical foundations and effective standardized assessments, ICT literacy will continue to play a fourth, barely audible fiddle to its three more established counterparts.

\section{References}

Association of College and Research Libraries. (2003). Information literacy competency standards for higher education. American Library Association. Retrieved January 31, 2010, from: http://www.ala.org/ala/mgrps/divs/acrl/standards/standards.pdf

Australian Ministerial Council on Education, Employment, Training and Youth Affairs. (2007). Information and communication technologies literacy: Years 6 and 10 report 2005. Retrieved January 31, 2010, from: http://www.mceecdya.edu.au/mceecdya/nap_ictl_2005_years_6 and_10 reportpress_release, $22065 . \mathrm{html}$

Bloom, B. S. (1956). Taxonomy of educational objectives, Handbook I: The cognitive domain. New York: David McKay Co Inc.

Braddlee, D., \& Matthews-DeNatale, G. (2006). Fluency in information technology (FIT): Setting expectations and understanding students' learning needs. Retrieved January 31, 2010, from http://connect.educause.edu/Library/Abstract/FluencyinInformationTechn/42229

California Emerging Technology Fund (2008). California ICT digital literacy assessments and curriculum framework. CETF ICT Digital Literacy Initiative - Consensus Document. Retrieved January 31, 2010, from:

http://www.ictliteracy.info/rf.pdf/California\%20ICT\%20Assessments $\% 20$ and $\% 20$ Curriculum $\% 20$ Fra mework.pdf 
Cesarini, P. (2004/2005). Computers, technology, and literacies. Journal of Literacy \& Technology, 4(1). Retrieved January 31, 2010, from http://www.literacyandtechnology.org/volume5/Cesarini.pdf

Cohen, E. (1987). What is computer literacy: the sham, the imposter, and the misdirected. Proceedings of the 15th Annual Conference on Computer Science, St. Louis, MO, USA, 320-322.

Dednam, E. (2009). Away with computer literacy modules at universities, or not? Proceedings of the 2009 Annual Conference of the Southern African Computer Lecturers' Association, Eastern Cape, South Africa, 23-32.

Ehmann, S. (2004). Beyond computer literacy: Implications of technology for the content of a college education. Liberal Education, 90(4), 6-13.

Erikson, E. (1950). Childhood and society. New York: W. W. Norton and Co.

Gupta, G. K. (2006). Computer literacy: Essential in today's computer-centric world. SIGCSE Bulletin, $38(2), 115-119$.

Halaris, A., \& Sloan, L. (1985). Towards a definition of computing literacy for the liberal arts environment. Proceedings of the 16th SIGCSE Technical Symposium on Computer Science Education, New Orleans, LA, USA, 320-326.

Hilberg, J. S., \& Meiselwitz, G. (2008). Undergraduate fluency with information and communication technology: perceptions and reality. Proceedings of the 9th ACM SIGITE Conference on Information Technology Education, Cincinnati, OH, USA, 5-10.

Hoffman, M., Blake, J., McKeon, J., Leone, S., \& Schorr, M. (2005). A critical computer literacy course. Journal of Computing Sciences in Colleges, 20(5), 163-175.

ICT Literacy Panel. (2007). Digital transformation: A framework for ICT literacy. Princeton, NJ: Educational Testing Service. Retrieved January 31, 2010, from: http://www.ets.org/Media/Tests/Information and_Communication_Technology_Literacy/ictreport.pdf

Jonassen, D. H., \& Land, S. M. (2000). Theoretical foundations of learning environments. Mahwah, NJ: Lawrence Erlbaum Associates.

Katz, I. R. and Macklin, A. S. (2007). Information and communication technology (ICT) literacy: Integration and assessment in higher education. Systemics, Cybernetics and Informatics, 5(4), 50-55.

Lykos, P. G., Morgan, M. G., \& Weingarten, F. W. (1973). Computer impact on society: Perspective on a new NSF initiative. Proceedings of the ACM Annual Conference, Atlanta, GA, USA, 374-380.

Madigan, E. M., Goodfellow, M., \& Stone, J. A. (2007). Gender, perceptions, and reality: Technological literacy among first-year students. Proceedings of the 38th SIGCSE Technical Symposium on Computer Science Education, Covington, KY, USA, 410-414.

Markauskaite, L. (2006). Towards an integrated analytical framework of information and communications technology literacy: From intended to implemented and achieved dimensions. Information Research, 11(3), 252. Retrieved January 31, 2010, from http://InformationR.net/ir/11-3/paper252.html

Mason, J., \& Morrow, R. M. (2006). YACLD: Yet another computer literacy definition. Journal of Computing in Small Colleges, 21(5), 94-100.

Measuring 21st Century Skills. (2009). eSchool News. Retrieved January 31, 2010, from http://www.eschoolnews.com/resources/measuring-21st-century-skills/

Murray, M., \& Pérez, J. (2006). Can Johnny compute? The state of information technology assessment in higher education. Proceedings of the 13th International Academy for Information Management Conference, Milwaukee, WI, USA.

National Assessment Governing Board. (2009). 2012 NAEP technological literacy framework - 11/04/09 discussion draft. Retrieved January 31, 2010, from: http://www.edgateway.net/cs/naepsci/view/naep_nav/9 
Necessary, J. R., \& Parish, T. S. (1996). The relationships between computer usage and computer-related attitudes and behaviors. Education, 116(3), 384-386.

Neill, M. J. (1977). Some thoughts on reasons, definitions and tasks to achieve "functional" computer literacy. SIGCSE Bulletin, 9(1), 175-177.

Oblinger, D. G., \& Hawkins, B. L. (2006). The myth about student competency. EDUCAUSE Review, $41(2), 12-13$.

Pérez, J., \& Murray, M. (2006). Journey to the center of the core: Computers and the Internet in the core curriculum. The Information Universe: Issues in Information Science and Information Technology, 3, 489-498.

Smith, S., Salaway, S., \& Caruso, J. B. (2009). The ECAR study of undergraduate students and information technology, 2009 (Research Study, Vol. 6). Boulder, CO: EDUCAUSE Center for Applied Research. Retrieved January 31, 2010, from http://www.educause.edu/ecar

Spence, R., \& Smith, M. (2009). A dialogue on ICTs, human development, growth and poverty reduction: A background paper. The Harvard Forum. Berkman Center for Internet \& Society at Harvard University and Canada's International Development Research Centre. Retrieved January 31, 2010, from: http://publius.cc/dialogue_icts_human_development_growth_and_poverty_reduction/091109

Stiller, E., \& LeBlanc, C. (2006). From computer literacy to cyber-literacy. The Journal of Computing Sciences in Colleges, 21(6), 4-13.

U.S. Department of Education. (1996). Technological literacy. Retrieved January 31, 2010, from: http://www.ed.gov/updates/PresEDPlan/part11.html

Wen, J. R., \& Shih, W. L. (2008). Exploring the information literacy competence standards for elementary and high school teachers. Computers \& Education, 50(3), 787-806.

Zittrain, J. L. (2006). The generative Internet. Harvard Law Review, 119, 1974-2040.

\section{Biographies}

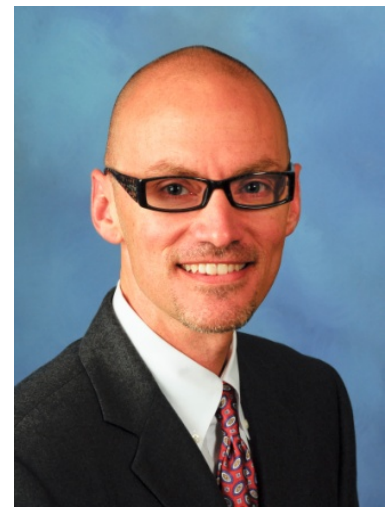

Jorge Pérez is Faculty Executive Assistant to the President and Associate Professor of Information Systems at Kennesaw State University. He holds a Ph.D. in Information Systems from Florida State University, and has two decades of experience in the field as a consultant, systems analyst, web developer, and educator. Professor Pérez has published research on information security, diffusion of innovations, information systems curriculum, and e-learning. His current research on information technology literacy centers on identifying, measuring, and amplifying competencies needed by computer and Internet users. 


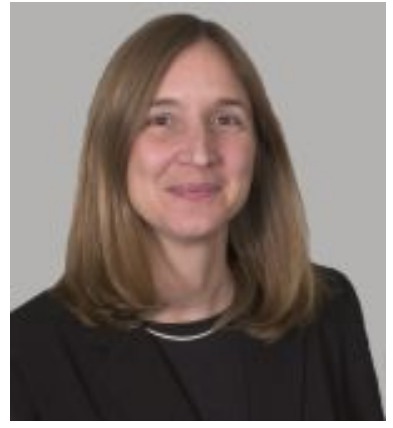

Meg Coffin Murray is an Associate Professor in the Department of Computer Science and Information Systems at Kennesaw State University. She holds a Ph.D. in Information Systems and has over thirty years of experience in both academe and industry. Dr. Murray specializes in the development and implementation of emerging technologies to meet business needs, with a special interest in technology infusion in healthcare. Her current work devises strategies to assess and remediate skills needed to leverage IT in innovation, a primary driver of economic growth. 